\section{Acknowledgment}

This research was supported by a National Science Foundation Presidential Young Investigator Award No. CTS 88-57037 and by Semiconductor Research Corporation under contract No. 93-SJ-340.

Manuscript submitted May 30, 1995; revised manuscript received Aug. 22, 1995.

University of Illinois assisted in meeting the publication costs of this article.

\section{REFERENCES}

1. S. P. Murarka, J. Vac. Sci. Technol., B4, 1325 (1986), and references cited therein.

2. A. G. Nassiopoulos and D. Tambouris, J. Appl. Phys., 72, 4660 (1992).

3. G. C. Xing and M. C. Ozturk, Mater, Lett, 17, 379 (1993).

4. M. E. Alperin, T. C. Hollaway, and R. A. Hakey, $I E E E$ Trans. Electron. Devices, ED-32, 141 (1985)

5. V. Q. Ho and D. Paulin, J. Vac. Sci. Technol., A5, 1396 (1987).

6. N. A. Kiselev, O. J. Lebedev, A. L. Vasiliev, A. A. Orlikovsky, K. A. Valiev, and A. G. Vasiliev, Vacuum, 44, 143 (1993).

7. A. Manenschiju, G. C. A. M. Janssen, E. van der Drift and S. Radelaar, J. Appl. Phys., 65, 3226 (1989).

8. W. L. O'Brien, T. N. Rhodin, and L. C. Rathbun, J. Vac. Sci. Technol., A6, 1384 (1988)

9. M. A. Jaso, S. W. Robey, and G. S. Oehrlein, This Journal, 136, 3812 (1989).

10. P. E. Riley, J. E. Turner, and K. K. Young, ibid., 140, L12 (1993)

11. G. Tomkins, M. H. Davis, and P. J. Rosser, Vacuum, 34, 451 (1984).

12. S. W. Robey, M. A. Jaso, and G. S. Oehrlein, J. Appl. Phys., 65, 2951 (1989).
13. G. S. Oehrlein and J. F. Rembetski, IBM J. Res. Develop., 36, 140 (1992).

14. A. Szabo and 'T. Engel, J. Vac. Sci. Technol., A12, 648 (1994).

15. T. Ono, H. Kashima, S. Hiraoka, and K. Suzuki, ibid, B9, 2798 (1991)

16. F. X. Campos, G. C. Weaver, C. J. Waltman, and S. R. Leone, ibid., B10, 2217 (1992).

17. M. A. Mendicino and E. G. Seebauer, Appl. Surf. Sci., 68, 285 (1993)

18. R. P. Southwell and E. G. Seebauer, J. Vac. Sci. Technol., A13, 221 (1995).

19. J. Lee and R. Reif, J. Electron. Mater, 20, 332 (1991).

20. M. A. Mendicino and E. G. Seebauer, J. Cryst. Growth 134, 377 (1993) and references cited therein.

21. M. A. Mendicino and E. G. Seebauer, This Journal, 140, 1786 (1993).

22. M. J. M. Vugts, G. J. P. Joosten, A. Vanoosterum, and H. A. J. Senhorst, J. Vac. Sci. Technol., A12, 2999 (1994).

23. M. Chen, V. J. Minkiewicz, and K. Lee, This Journal, 126, 1946 (1979)

24. J. A. Mucha, V. M. Donnelly, D. L. Flamm, and L. M. Webb, J. Chem. Phys, 85, 3529 (1981).

25. M. A. Mendicino, R. P. Southwell, and E. G. Seebauer, Thin Solid Films, 253, 473 (1994).

26. R. P. Southwell and E. G. Seebauer, Surf. Sci., 329, 107 (1995).

27 R. P. Southwell and E. G. Seebauer, ibid., In press

28. M. A. Mendicino and E. G. Seebauer, ibid., 277, 89 (1992).

29. M. A. Mendicino and E. G. Seebauer, J. Vac. Sci. Technol., A10, 3590 (1992).

30. C. M. Chan, R. Aris, and W. H. Weinberg, Appl. Surf. Sci., 1, 360 (1978).

31. G. J. Reynolds, C. B. Cooper III, and P. J. Gaczi, J. Appl. Phys., 65, 3212 (1989).

\title{
Rapid Thermal Annealing Behavior of Amorphous SiC Layers Deposited by Electron Cyclotron Resonance Plasma
}

\author{
F. J. Gomez, J. Garrido, J. Martinez, and J. Piqueras ${ }^{\circ}$ \\ ${ }^{a}$ Laboratorio de Microelectrónica, Departamento de Fisica Aplicada and Departamento de Ingeniería Informática, \\ Universidad Autónoma de Madrid, 28049 Madrid, Spain
}

\begin{abstract}
Hydrogenated amorphous silicon carbide, a-SiC:H, has been deposited by electron cyclotron resonance plasmas. Operating in methane excess $\left(\mathrm{CH}_{4} / \mathrm{SiH}_{4}\right.$ flow ratios between 2 and 4$)$ and at high enough microwave powers, the deposited SiC films are close to stoichiometric. In these $\mathrm{SiC}$ layers, only small traces of the $\mathrm{CH}_{n}$ and $\mathrm{SiH}_{n}$ stretching bands can be detected. Rapid thermal annealing leads to nearly complete dehydrogenation of the SiC layers deposited under these conditions as deduced from ellipsometric and infrared spectroscopy.
\end{abstract}

\section{Introduction}

Currently, there is much interest in the preparation methods of hydrogenated amorphous silicon carbide, a-SiC:H. Beside its chemical inertness, hardness, and radiation resistance, the energy gap and thus its electronic and optical properties can be continuously changed by controlling the composition and the hydrogen content. These properties make possible a wide variety of applications. Nowadays, a-SiC:H is being considered as the base material for such applications as solar cells, thin film transistors, photodetectors, flat panel displays, and, more recently, x-ray masks to mention a few.

Among the different techniques, those based on plasmaenhanced chemical vapor deposition (PECVD) are becoming widely used for a-SiC:H film growth. Both standard radio-frequency ${ }^{1-5}$ and electron cyclotron resonance $(\mathrm{ECR})^{6,7}$ deposition techniques are being extensively investigated.
Because the precursor gases are usually silane, methane, or other low molecular weight carbon bearing species, hydrogen is incorporated into the film if the deposition takes place at low temperature. Dehydrogenation after deposition is required to relax the film stress if the deposited SiC layers are to be used for $\mathrm{X}$-ray mask technology. ${ }^{8-10}$ However, the ease of hydrogen release during subsequent heat-treatments depends on the $\mathrm{SiC}$ composition and on the way in which hydrogen is bonded. In the carbon-rich region, hydrogen may be found in different environments; however, most of them involve $\mathrm{CH}_{n}$ radicals. In the silicon-rich region, one or two hydrogen atoms may be bonded to one silicon atom. ${ }^{1}$ Additionally, in silicon-rich compositions, $\mathrm{CH}_{3}$ radicals are commonly found. The incorporation of methyl groups into the film may lead to microvoid formation during the subsequent annealing and to the deterioration of $\mathrm{SiC}$ optoelectronic properties. ${ }^{3,11}$ 
In this work we report ECR plasma deposition of a-SiC:H films from methane and silane as precursors under different deposition conditions. The SiC films are deposited at low temperature, $150^{\circ} \mathrm{C}$, and later subjected to rapid thermal annealing (RTA). Fourier transform infrared (FTIR) spectroscopy has been used to investigate the hydrogen containing radicals incorporated into the film and their evolution with heat-treatments. The dielectric constants of the films have been calculated from spectroscopic ellipsometry. Both kinds of measurements have been used to estimate the layer composition.

\section{Experimental}

A "low profile" ECR plasma system from Plasma Quest has been used to deposit the a-SiC:H layers. In this low profile reactor one of the electromagnets is placed in the neighborhood of the sample holder. ${ }^{12}$ This enables the achievement of well-shaped plasma columns assuring good ion current uniformity on the sample. In this way, thickness homogeneities better than $10 \%$ over 4 in. slices have been obtained. A load lock chamber and a high pumping speed turbomolecular pump enable background pressures $<10^{-7}$ Torr.

The different gases are introduced through mass flow controllers. A flow of $100 \mathrm{sccm}$ of pure argon is introduced in the resonance region to form the plasma column while the reactive gases, pure $\mathrm{CH}_{4}$ and $5 \%$ argon diluted $\mathrm{SiH}_{4}$, are introduced by a second gas inlet in the proximity of the substrate holder. Pure silane flow was varied between 2.5 and $5 \mathrm{sccm}$, while $\mathrm{CH}_{4}$ flow was $10 \mathrm{sccm}$. For these $\mathrm{CH}_{4} / \mathrm{SiH}_{4}$ flow ratios, 2 or 4 , only small traces of the $\mathrm{SiH}_{2}$ and $\mathrm{CH}_{n}$ stretching bands are observed by infrared spectroscopy and the deposited silicon carbide is close to stoichiometric as we have previously reported. ${ }^{13}$ The pressure in the work chamber was maintained between 1 and $3 \mathrm{mTorr}$ in all the experiments. Under these conditions, reactions between the precursor gases and nucleation inside the plasma are largely prevented. In this way, very compact layers are expected. Different SiC layers were deposited varying the microwave power between 500 and $1500 \mathrm{~W}$. In all cases $<5 \%$ of the incident power was reflected.

Substrates were (100) p-type Si slices. Prior to loading in the vacuum chamber, the Si substrates were degreased and the native oxide removed with ethanol diluted $\mathrm{HF}$.
Once the samples were loaded, a pure argon plasma was formed for a few seconds, and subsequently $20 \mathrm{sccm}$ of $\mathrm{CH}_{4}$ were added for $30 \mathrm{~s}$ to assure that the starting Si surface was completely covered with methane radicals. Finally, the flows of both precursors were set to the desired values. During deposition, the temperature of the sample was maintained at approximately $150^{\circ} \mathrm{C}$.

After deposition the samples were cut into small pieces and annealed for $3 \mathrm{~min}$ in an RTA system under vacuum at temperatures between 500 and $1200^{\circ} \mathrm{C}$. The heat-treated samples were later characterized by FTIR spectroscopy and spectroscopic ellipsometry.

Infrared spectroscopy was performed in the reflectionabsorption mode using an uncoated Si sample as a reference. The Si reference sample was freshly prepared in an HF:ethanol mixture and later rinsed in pure ethanol to avoid a quick formation of native oxide. To avoid reflections from the back surfaces, roughened rear side slices were used. The band areas of the different stretching modes were used to get qualitative information on the layer composition disregarding multiple reflections at the interfaces. This may give rise to errors of about $10 \%$. $^{1,14}$

In the samples deposited with a flow ratio of 4 , the deposition time was varied between 90 and $135 \mathrm{~s}$ to get a thickness of $\sim 500 \AA$. For this thickness range the ellipsometric curves are free from interferences and it is possible to get a good estimation of the layer composition. This may be compared with that obtained from infrared measurements. ${ }^{15}$

The dielectric constant of the layers is obtained from the ellipsometry measurements between 1.5 and $4.5 \mathrm{eV}$. In this energy range and for these thicknesses, the experimental errors of the ellipsometric angles $\Psi$ and $\Delta$ are very low. An air/layer/substrate structure was used to simulate the ellipsometric spectra using the available data from the literature. ${ }^{16,17}$ The thicknesses obtained in this way were checked against direct measurements of step heights with a profilometer for some samples. In all cases, there was good agreement.

The procedure for obtaining the optical constants $n$ and $k$ of the SiC layers is essentially as follows. Based on accepted values of the optical parameters $n$ and $k$ for $\mathrm{Si}$, and experimental values of $\Psi^{\mathrm{m}}$ and $\Delta^{\mathrm{m}}$, a pair of trial values, $n_{+}$and $k_{\text {t }}$, for the film were estimated. These values were introduced in the ellipsometric equations of the
Fig. 1. Real, $\epsilon_{\mathrm{r}}$ and imaginary, E. dielectric constants of a sample deposited with a $\mathrm{CH}_{4} / \mathrm{SiH}_{4}$ How ratio $r=4$ and $1000 \mathrm{~W}$ microwave power. Squares and circles are experimental points and lines represent the simulated spectra. Continuous line is the simulated spectrum of a $568 \AA$ thickness layer with $77 \% \mathbf{S i C}_{\text {, }}$ $22 \%$ void, and $1 \%$ a-Si. Dashed line is the simulated spectrum of a film 387 A thick with $89 \% \mathrm{SiC}$, $1 \%$ yoid, and $10 \%$ of a-Si with o $22 \dot{\mathrm{A}} \mathrm{SiO}_{2}$ top loyer.

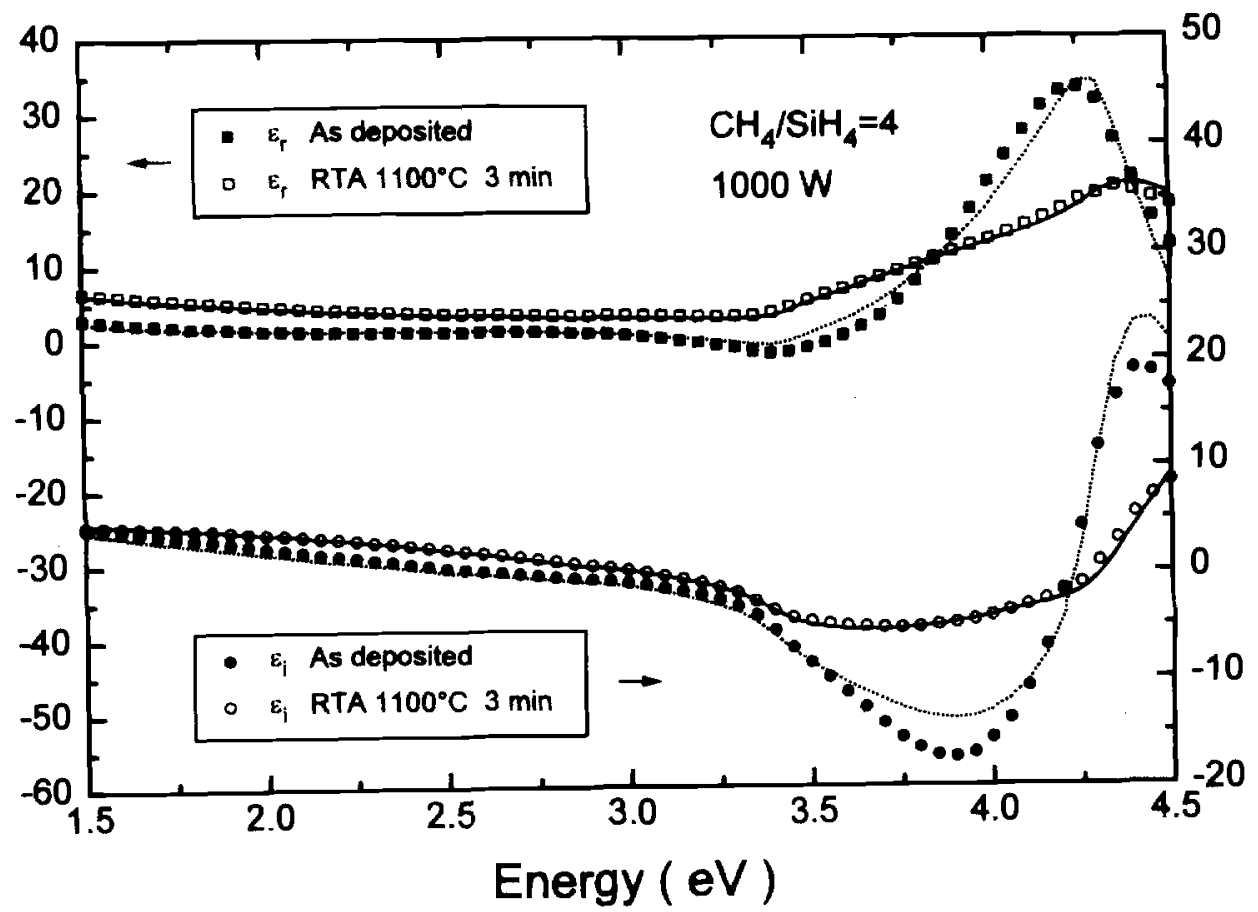


reflected beam for an air/film/substrate structure. Numerical inversion of these equations gives two trial values of $\Psi^{t}$ and $\Delta^{t}$. With these values and the experimental ones an error function defined $\mathrm{as}^{18}$

$$
G=\left(\Delta^{t}-\Delta^{m}\right)^{2}+\left(\Psi^{t}-\Psi^{m}\right)^{2}
$$

was minimized. With this algorithm, error values $<10^{-4}$ for each experimental point may be obtained.

\section{Results \\ Ellipsometry}

The simulated spectra were fit to the experimental ones leaving the layer composition and thickness as adjustable parameters. To estimate the composition, it was assumed that the layer consists essentially of $\mathrm{SiC}$ and voids. The addition of a small content of amorphous silicon to the $\mathrm{SiC}$ layer and a very thin $\mathrm{SiO}_{2}$ layer on top of the structure often improved the accuracy of the fit. The best fit parameters obtained in this way were taken as measures of the thickness and composition of the SiC layer.

In Fig. 1 two examples of such fits are shown. Solid squares and circles correspond to a sample deposited with flow ratio of 4 and $1000 \mathrm{~W}$ of microwave power. The same sample, after an RTA for $3 \mathrm{~min}$ at $1100^{\circ} \mathrm{C}$ under vacuum, is represented by open squares and circles. Generally, the fits of the simulated spectra to the experimental ones seemed to be better after the heat-treatments than those of asdeposited samples.

Comparing continuous to dashed lines and the corresponding best fit parameters, it can be seen that, after annealing, the thickness of the SiC layer and the void content decreased whereas the percentage of $\mathrm{SiC}$ increased. This compaction is accompanied by the appearance of a certain amount of a-Si and a thin $\mathrm{SiO}_{2}$ layer on top of the structure. This behavior was qualitatively maintained throughout all the samples.

Figure 2 shows the thickness variation with the annealing temperature of several samples deposited with a flow ratio of 4 and microwave powers between 500 and $1500 \mathrm{~W}$. As can be seen, the relative compaction was similar for all values of microwave power and mostly occurs between 500 and $900^{\circ} \mathrm{C}$.

The top oxide formation was negligible in the samples deposited with the highest microwave power regardless of the annealing temperature. The thickness of this oxide layer seems to increase with decreasing microwave powers for a given annealing temperature. Anyway, the estimated $\mathrm{SiO}_{2}$ thickness was always $<40 \AA$.

The growth rates have been obtained from the deposition time and thickness. Figure 3 shows the growth rate $v s$. microwave power for $10 \mathrm{sccm}$ of $\mathrm{CH}_{4}$ and $2.5 \mathrm{sccm}$ of $\mathrm{SiH}_{4}$ flows. The deposition rate increases linearly with the microwave power. The $\mathrm{SiC}$ and void percentages estimat-

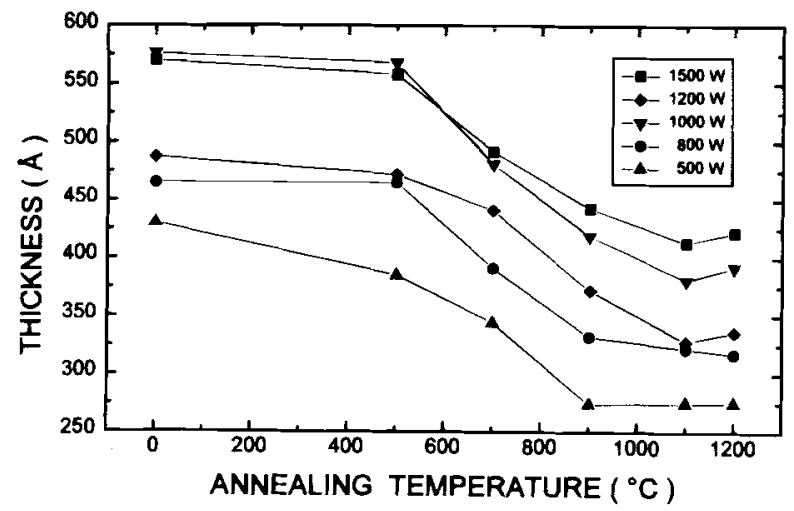

Fig. 2. Thickness of $\mathrm{SiC}$ layers deposited with different microwave powers plotted against annealing temperature. Lines are drown as a guide for the eye.

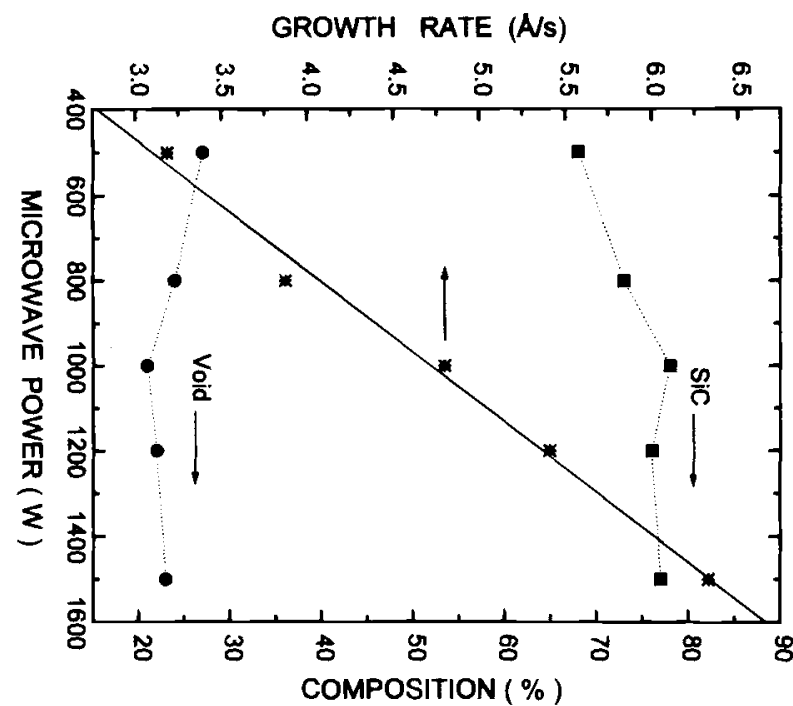

Fig. 3. Growth rate vs. microwave power. Also included is the composition of as-deposited SiC layers. The percentage of a-Si is not shown.

ed from the best fits to the ellipsometric spectra of the asdeposited samples also are shown in Fig. 3. As expected the void content decreases for increasing microwave powers as the SiC percentage increases. Only for the lowest microwave powers was the addition of small amounts of a-Si required to get reasonable fits.

The composition deduced from ellipsometry has been followed with the annealing temperature. The $\mathrm{SiC}$ and void percentages of three samples deposited with 500,800 , and $1500 \mathrm{~W}$ have been plotted in Fig. 4. The rest of the total is the a-Si content. As can be seen, the void content decreases with increasing temperature and becomes almost zero at 1100 or $1200^{\circ} \mathrm{C}$. This decrease is more abrupt at higher microwave powers. However, the increase in $\mathrm{SiC}$ percentage with annealing temperature did not cor-

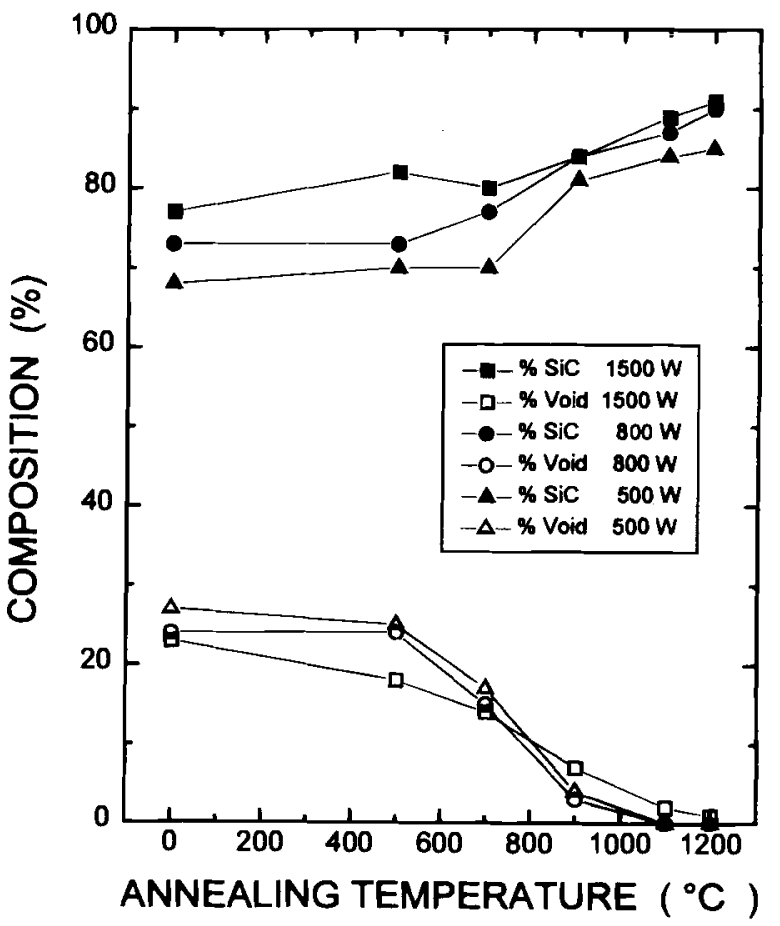

Fig. 4. Composition of SiC layers plotted against annealing temperature. The percentage of a-Si is not shown. 


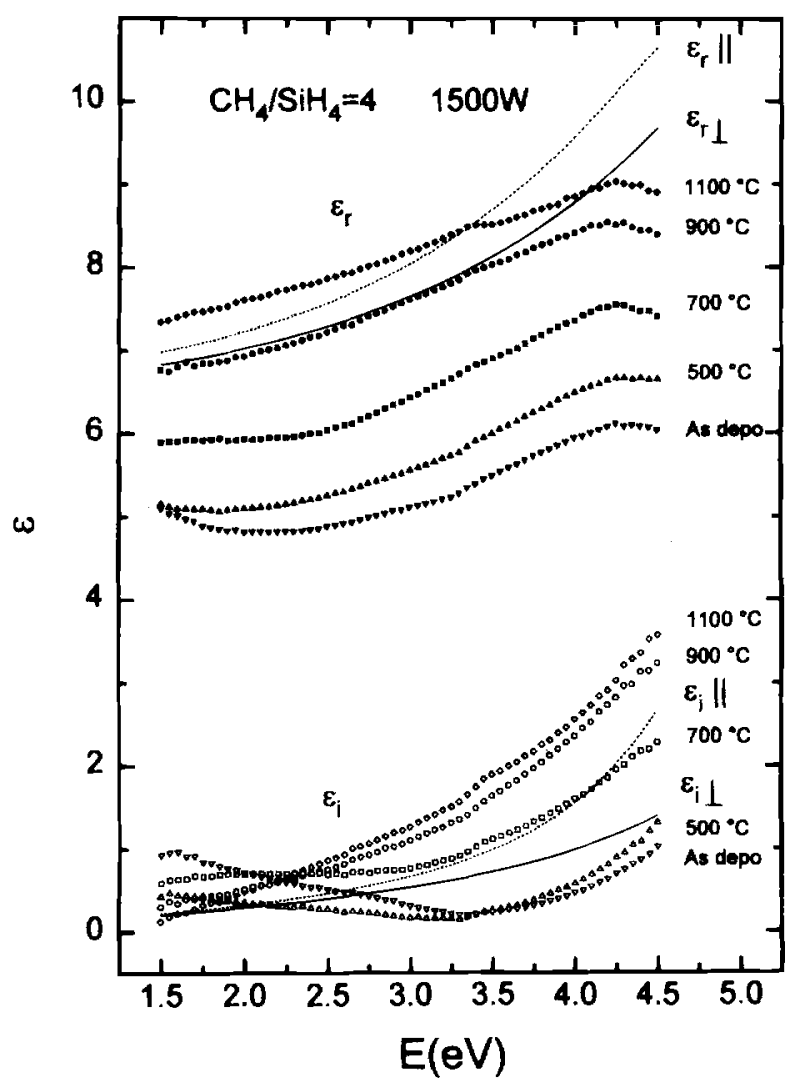

Fig. 5. Dielectric constant of layer for various annealing temperatures. Continuous and broken lines represent the dielectric constant according two and three oscillators models, respectively.

respond exactly to the void decrease, and it was necessary to include a certain amount of a-Si to fit the experimental ellipsometric curves accurately. This amount of a-Si was very small in the as-deposited samples but increased to approximately 10 to $15 \%$ at $1200^{\circ} \mathrm{C}$ depending on the microwave power.

To compare with the available data from the literature, we have calculated the dielectric constant of the isolated $\mathrm{SiC}$ layers following the inversion procedure described above. In Fig. 5, both real and imaginary parts of the dielectric constant are plotted as a function of the energy Dielectric constants of the annealed and as-deposited samples are included in Fig. 5. Also included (lines) are the results recently published by Ninomiya and Adachi ${ }^{19}$ in bulk hexagonal $6 \mathrm{H}-\mathrm{SiC}$. Continuous lines represent the dielectric constants normal to the hexagonal axis whereas dashed lines correspond to a direction parallel to the hexagonal axis. To plot both curves, we have used the fitting parameters obtained by the authors ${ }^{19}$ using the classical Lorentz-type damped oscillator model. The calculation of normal dielectric constant, $\epsilon_{\perp}$, includes two oscillators whereas an additional one is required to fit the parallel dielectric constant, $\epsilon_{\| 1}$, accurately. As can be seen in Fig. 5, the real part of the dielectric constant of SiC films annealed at 900 and $1100^{\circ} \mathrm{C}$ compares favorably with recently reported data ${ }^{19}$ up to energies $-3.5 \mathrm{eV}$ whereas the low temperature annealed and as-deposited films have a dielectric constant below these reported results. The agreement between $\epsilon_{\mathrm{I},}$ and the curve corresponding to $900^{\circ} \mathrm{C}$ is remarkable. The imaginary part of the measured dielectric constant of the SiC films differs from the calculated values $\left(\epsilon_{\mathrm{i} \perp}\right.$ and $\left.\epsilon_{\mathrm{ill}}\right)$ at all annealing temperatures.

\section{Infrared Spectroscopy}

Infrared measurements were performed in the reflection-absorption mode at near normal incidence, $15.2^{\circ}$,

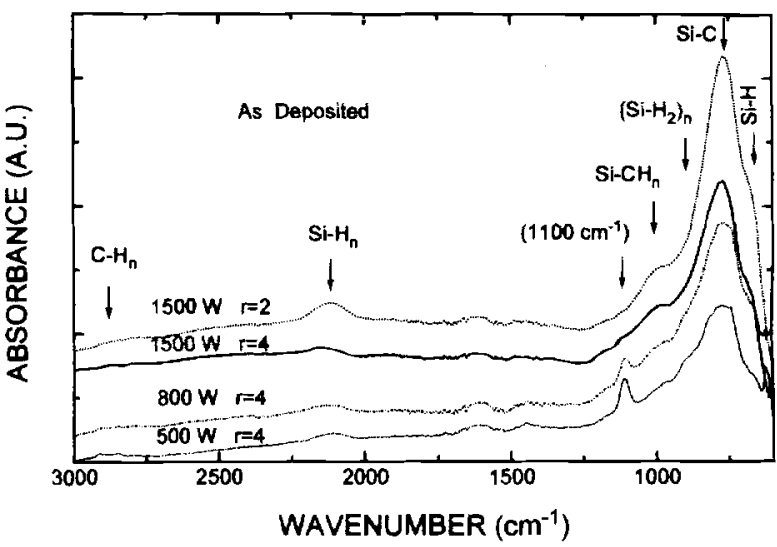

Fig. 6. Infrared spectra of SiC layers as deposited ( $r$ is the ratio between $\mathrm{CH}_{4}$ and $\mathrm{SiH}_{4}$ flow).

using a freshly prepared $\mathrm{Si}$ substrate as a reference. Frequency resolution was limited to $4 \mathrm{~cm}^{-1}$ to minimize interference due to reflection from the back surface.

Figure 6 shows typical spectra of four samples deposited with flow ratios 2 and 4 and different microwave powers. There is not much difference between the spectra of the two samples deposited at the maximum power and with flow ratios of 2 and 4 , except in the band around $2100 \mathrm{~cm}^{-1}$ assigned to $\mathrm{SiH}_{n}$ stretching vibrations. ${ }^{20,21}$ The smaller the flow ratio the larger the $\mathrm{SiH}_{n}$ band that is observed, as we have previously reported ${ }^{13}$ The nearly complete absence of the $\mathrm{CH}_{n}$ stretching band at around $2900 \mathrm{~cm}^{-1} 2,14,22$ under these conditions is noteworthy. Small traces of the $\mathrm{CH}_{n}$ stretching band appeared only in the samples deposited at low powers and with a flow ratio of 4 .

Also at low microwave powers, 500 and $800 \mathrm{~W}$, and for $r=4$, a band around $1100 \mathrm{~cm}^{-1}$ appeared. When this band is present in the as-deposited sample, it cannot be removed completely by later heat-treatments. Because the most intense absorption band in PECVD $\mathrm{SiO}_{2}$ films appears at $1070 \mathrm{~cm}^{-1},{ }^{23}$ it may be thought that the residual water vapor in the reaction chamber may be responsible for the $\mathrm{Si}-\mathrm{O}$ bond formation. However, incomplete reaction between the $\mathrm{Si}$ and $\mathrm{C}$ radicals, due to the low microwave powers, may lead to the formation of complex functional groups of the type $\left(\mathrm{CH}_{m}\right)_{n} \mathrm{C} / \mathrm{Si}(m=2-3, n=1-3)$ as suggested by other authors. ${ }^{21,24-27}$ Similar bands have been observed recently by Rynders et al. ${ }^{28}$ in PECVD a-SiC:H films deposited using tetramethylsilane.

The main band at $780 \mathrm{~cm}^{-1}$ present in all the spectra is undoubtedly related with the Si-C stretching vibration, ${ }^{6,14}$ At low deposition powers, this band is considerably broadened probably due to bond angle distortions ${ }^{29}$ or to the contribution of the $\mathrm{Si}-\mathrm{CH}_{3}$ rocking or wagging modes. ${ }^{21,29}$ As the deposition power is increased, this band is narrowed and slightly shifted toward larger wave numbers. Further, as the power increases, several shoulders clearly appear at the right and left sides of this band. In the low wave number side, around $670 \mathrm{~cm}^{-1}$, a shoulder generally assigned to the $\mathrm{Si}-\mathrm{H}$ rocking or wagging modes appears. ${ }^{29}$ In the left side, two additional shoulders appear more or less clearly depending on the deposition conditions. The shoulder at $915 \mathrm{~cm}^{-1}$ may be due to $\left(\mathrm{SiH}_{2}\right)_{n}$ bending modes ${ }^{1}$ whereas the other at around $1000 \mathrm{~cm}^{-1}$ could be related to wagging vibrations of $\mathrm{CH}_{n}$ bonds in $\mathrm{Si}-\mathrm{CH}_{n}$ groups. ${ }^{1,29,30}$

After annealing, even at low temperatures, all the bands except those around $780 \mathrm{~cm}^{-1}$ disappeared completely. As an example, Fig. 7 shows the spectra of a sample deposited with $1500 \mathrm{~W}$, and $r=2$ after several heat-treatments. The spectrum of the as-deposited sample is included for comparison. As can be seen, the main band is considerably 


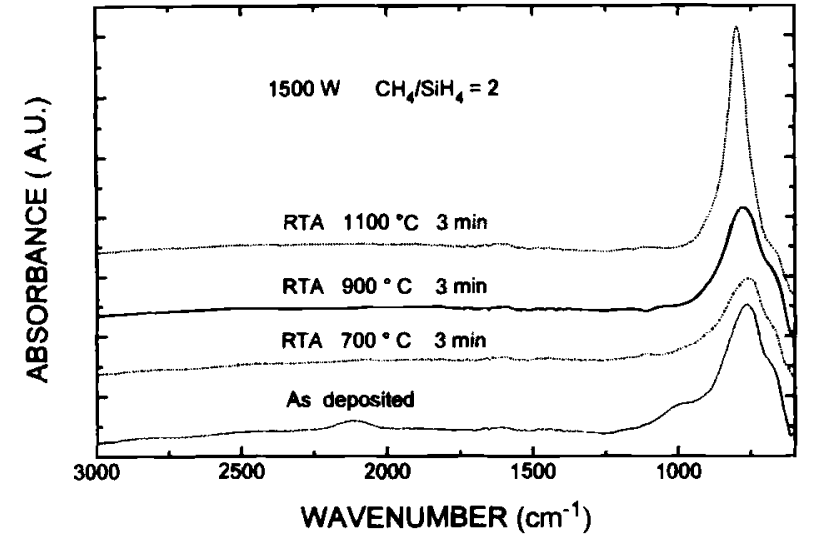

Fig. 7. Infrared spectrum for several annealing temperatures of a sample deposited at $1500 \mathrm{~W}$ with a flow ratio $\mathrm{CH}_{4} / \mathrm{SiH}_{4}=2$.

narrowed and slightly shifted toward larger wave numbers as the annealing temperature increases.

The $\mathrm{CH}_{n}$ and $\mathrm{SiH}_{n}$ stretching bands disappear completely after low temperature annealings. This prevents a precise calculation of the annealed layer composition using the 780,2100 , and $2900 \mathrm{~cm}^{-1}$ bands. Thus, we have tried to follow qualitatively the composition evolution of the films across the changes of the $780 \mathrm{~cm}^{-1}$ band and its shoulders. For this purpose, we have deconvoluted this band into four Gaussian functions corresponding to the $\mathrm{Si}-\mathrm{C}$, $\left(\mathrm{SiH}_{2}\right)_{n}, \mathrm{Si}-\left(\mathrm{CH}_{n}\right)$, and $\mathrm{Si}-\mathrm{H}$ bands. Figure 8a shows the normalized area changes with the annealing temperature for a sample deposited with $r=4$ and $1500 \mathrm{~W}$. As can be seen, the Si-C band area increased from $70 \%$ in the asdeposited sample to $\sim 90 \%$ after the $1100^{\circ} \mathrm{C}$ annealing. At the same time, the hydrogen containing groups, $\left(\mathrm{SiH}_{2}\right)_{n}$
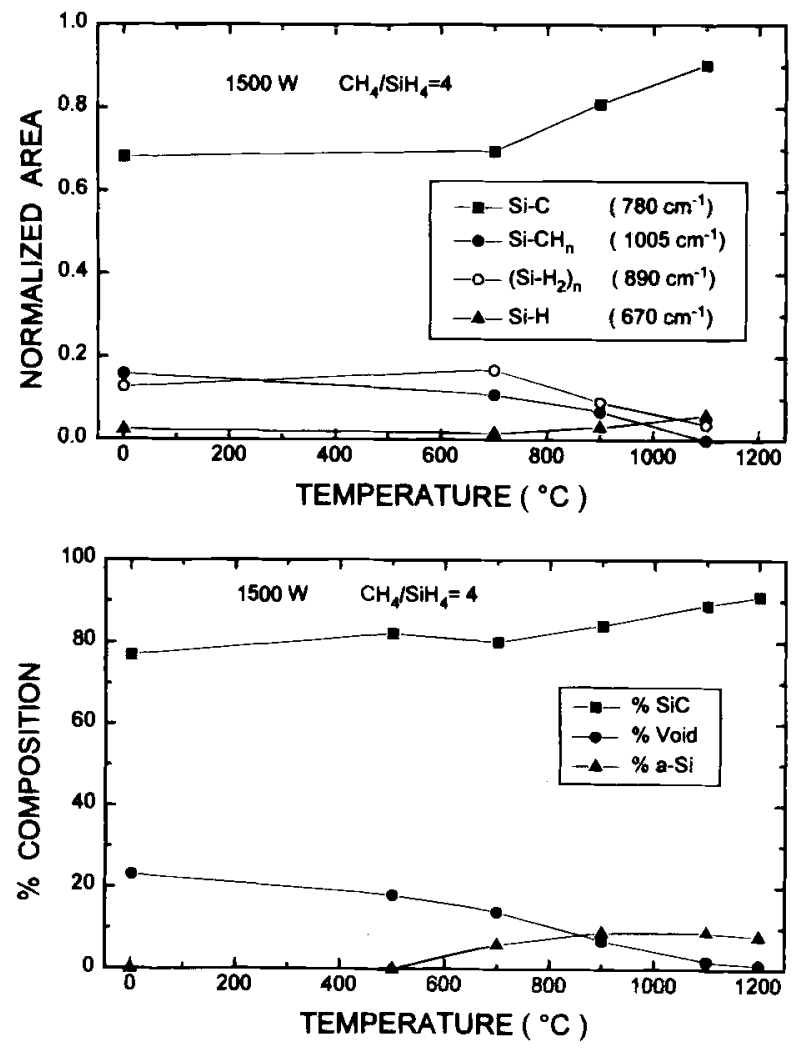

Fig. 8. (a, top) Normalized area of Si-C, Si-CH,$\left(\mathrm{Si}_{n}-\mathrm{H}_{2}\right)_{n}$ and Si-H bands vs. annealing temperature. (b, bottom) Percentages of SiC, a$\mathrm{Si}$, and voids obtained from ellipsometric data.

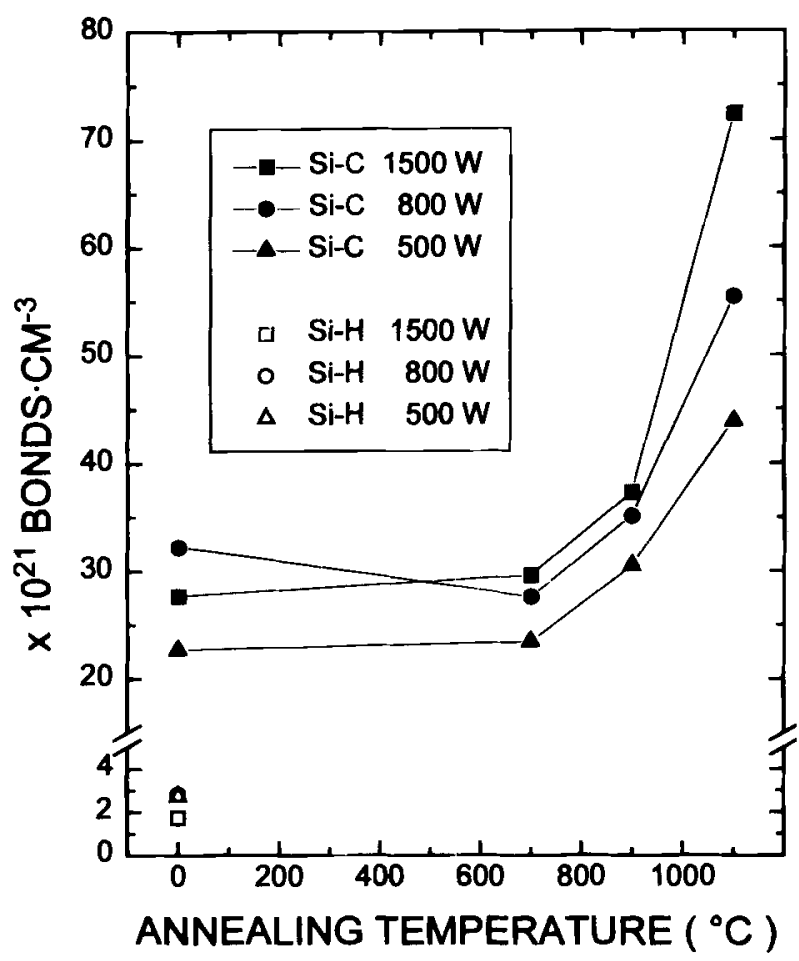

Fig. 9. Estimated Si-C and Si-H bond concentrations vs. annealing remperature.

and $\mathrm{Si}-\mathrm{CH}_{n}$, decreased from $\sim 15 \%$ to nearly zero. The only exception was the $\mathrm{SiH}$ band which seemed to increase with the annealing temperature. However too much confidence must not be put in this fact because this region is near the cutoff of the detector. For comparison we have plotted in Fig. 8b the compositions obtained from the fits of the ellipsometric spectra in the same samples. As can be seen, the percentage of SiC obtained from ellipsometry changes with the temperature in a similar fashion to the infrared (IR) Si-C normalized band area. The changes of the $\left(\mathrm{SiH}_{2}\right)_{n}$ and $\mathrm{Si}-\mathrm{CH}_{n}$ normalized band areas compare favorably with the decrease in void content in the annealed samples. Further, the a-Si concentration deduced from ellipsometry is correlated with the evolution of the IR band areas associated with the $\mathrm{Si}-\mathrm{H}$ rocking or wagging modes.

Using the $\mathrm{SiH}_{n}, \mathrm{CH}_{n}$, and $\mathrm{SiC}$ stretching mode bands and the thicknesses deduced from ellipsometry, the bond concentrations have been estimated, whenever is possible, using the formula

$$
N=A_{\mathrm{s}} \int \frac{\alpha(v)}{v} d v \cong \frac{A_{\mathrm{s}}}{v_{0}} \int \alpha(v) d v
$$

where $A_{\mathrm{s}}$ is the reciprocal of the cross section of a given vibration mode, $\nu_{0}$ is the center band wave number, and $\alpha(v)$ is the absorption coefficient. The $A_{\mathrm{s}}$ values have been taken from the literature

$$
\begin{aligned}
& A_{\mathrm{s}(\mathrm{Si}-\mathrm{H})}=1.4 \times 10^{20} \mathrm{~cm}^{-2} \\
& A_{\mathrm{s}(\mathrm{C}-\mathrm{H})}=1.35 \times 10^{21} \mathrm{~cm}^{-2} \\
& A_{\mathrm{s}(\mathrm{Si}-\mathrm{C})}=2.13 \times 10^{19} \mathrm{~cm}^{-2}
\end{aligned}
$$

The $\mathrm{SiH}_{n}$ and $\mathrm{CH}_{n}$ bond concentrations can be estimated only in the as-deposited samples because of the complete disappearance of these bands after a $700^{\circ} \mathrm{C} 3 \mathrm{~min}$ annealing. The $\mathrm{SiH}_{n}$ bond concentrations in the asdeposited samples were $\sim 2 \times 10^{21} \mathrm{~cm}^{-3}$ as can be seen in Fig. 9. The $\mathrm{CH}_{n}$ band is scarcely distinguishable from the noise even in the untreated samples deposited with the 
lowest powers but in these samples, the $\mathrm{CH}_{n}$ bond concentration may be roughly estimated to be, at maximum, in the $10^{21} \mathrm{~cm}^{-3}$ range. The $\mathrm{SiC}$ bond concentrations remain essentially unchanged up to $700^{\circ} \mathrm{C}$ but increase abruptly after this temperature. The rate of increase is larger as the deposition power increases. SiC bond concentrations in the upper $10^{22}$ bonds $\cdot \mathrm{cm}^{-3}$ range were obtained after $1100^{\circ} \mathrm{C}$ annealing. The bond density increase is consistent with the film compaction deduced from ellipsometry (see Fig. 2).

\section{Discussion}

Dehydrogenation of the SiC films depends strongly on the way in which hydrogen is bonded to $\mathrm{C}$ and $\mathrm{Si}$ atoms. Because the $\mathrm{C}-\mathrm{H}$ bond is much more stable than the $\mathrm{Si}-\mathrm{H}$ bond, the formation of $\mathrm{CH}_{n}$-like groups must be avoided as much as possible. Thus the methane-to-silane flow ratio must be as close as possible to unity to be near stoichiometry. However, based on the bond strength difference, the activation or ionization efficiency in the plasma is lower for methane than for silane. This forces us to operate under methane excess conditions to avoid having the SiC films deviate from stoichiometry toward Si-rich compositions as we have been reported previously. ${ }^{13}$ Further, for a given flow ratio, enough microwave energy must be supplied to the plasma; otherwise, a band around $1100 \mathrm{~cm}^{-1}$ arises, probably due to the formation of complex functional groups, $\left(\mathrm{CH}_{m}\right)_{n} \mathrm{C} / \mathrm{Si}$, that cannot be removed completely by later annealings. Under these conditions $\mathrm{CH}_{n}$ stretching vibrations are nearly undetectable. Only if $\mathrm{CH}_{n}$ is bonded to $\mathrm{Si}$, can it be observed in the form of wagging vibrations.

The $\mathrm{CH}_{n}$ wagging vibrations in $\mathrm{Si}-\mathrm{CH}_{n}$ groups disappear completely after high temperature annealings (Fig. 8a). Dehydrogenation of $\mathrm{CH}_{n}$ groups and later molecular hydrogen release from the film seem unlikely, because of the $\mathrm{C}-\mathrm{H}$ bond strength. More probably, $\left(\mathrm{SiH}_{2}\right)_{n}$ groups partially lose hydrogen which is transferred to $\mathrm{CH}_{n}$ groups and released in the form of methane. Further, part of the hydrogen lost from the $\left(\mathrm{SiH}_{2}\right)_{n}$ groups may be released in form of molecular hydrogen. The decrease of the $\left(\mathrm{SiH}_{2}\right)_{n}$ band to very small values (Fig. 8a) and the slight increase of the $\mathrm{SiH}$ rocking or wagging mode band is consistent with the suggested mechanism.

Moreover the composition changes of the SiC layer calculated from ellipsopmetric measurements are consistent with the above arguments. The decrease in the void content is accompanied by a slight increase in the a-Si percentage required to get accurate fits of the ellipsometric spectra (Fig. 8b). Both measurements suggest that small a$\mathrm{Si}: \mathrm{H}$ like regions may have been created by the hydrogen release during the high temperature treatments.

The dehydrogenation of the SiC layers, in addition to the compaction effect, probably leads to some structural changes in the amorphous network as suggested by the approach of its real dielectric constant to the crystalline $6 \mathrm{H}-\mathrm{SiC}$ values. To emphasize the possible structural changes, the Tauc's energy gaps have been obtained by appropriate manipulation of the imaginary part of the dielectric constant, that is, plotting $\epsilon^{1 / 2} E v s$. $E$. In the asdeposited samples, the energy gaps obtained are approximately $3 \mathrm{eV}$ and did not depend appreciably on the microwave power used for deposition. A $500^{\circ} \mathrm{C}$ annealing left the gaps essentially unchanged. After $700^{\circ} \mathrm{C}$ the gaps were reduced to values between 2.2 and $2.5 \mathrm{eV}$. Later heattreatments at higher temperatures did not give rise to significant additional changes of the energy gap values. The decrease in the energy gap may be explained by the reduction of the hydrogen content in the SiC films; however, deeper structural changes as the formation of microcrystalline regions inside the amorphous matrix cannot be ruled out completely. Further, the $\mathrm{SiC}$ stretching band is narrowed from a half width of $\sim 200 \mathrm{~cm}^{-1}$ in the asdeposited samples up to approximately $75 \mathrm{~cm}^{-1}$ after the highest annealing temperatures. This indicates a reduction of the bond angle distortion and, perhaps, some trend to crystallization.

\section{Conclusion}

Using $\mathrm{CH}_{4}$ and $\mathrm{SiH}_{4}$ precursors, ECR plasma deposition of stoichiometric $\mathrm{SiC}$ layers requires methane excess for achievement of good film quality. Further, for a given flow ratio, enough microwave energy must be supplied to the plasma to avoid the appearance of $\mathrm{CH}_{n}$ or other complex functional groups. Under these conditions, nearly complete dehydrogenation of the SiC layers may be achieved by high temperature annealings. Further to the dehydrogenation, the heat-treatments give rise to a compaction of the SiC films and, probably, to some structural changes as suggested by the changes of the dielectric constant and the estimated energy gap. The narrowing of the main IR SiC band also points to a reduction of the local disorder in the SiC network.

Manuscript submitted June 19, 1995; revised manuscript received Sept. 6, 1995 .

Universidad Antónoma de Madrid assisted in meeting the publication costs of this article.

\section{REFERENCES}

1. E. Gat, M. A. El Khakani, M. Chaker, A. Jean, H. Pepin, J. C. Kiefer, J. Durand, B. Cros, F. Rousseaux, and S. Gujrathi, J. Mater. Res., 7, 2478 (1992),

2. J. H. Park, H. S. Kwon, and J. Y. Lee, J. Appl. Phys., 72, 11 (1992)

3. J. Fölsch, H. Rübel, and H. Schade, ibid., 73, 8485 (1993).

4. M. A. El Khakani, M. Chaker, A. Jean, S. Boily, H Pepin, J. C. Kiefer, and M. Gujrathi, ibid., 74, 2834 (1993).

5. M. A. El Khakani, M. Chaker, A. Jean, S. Boily, J. C Kiefer, M. E. O'Hern, M. F. Ravetand, and F Rousseaux, J. Mater, Res., 9, 96 (1994).

6. A. Chayahara, A. Masuda, T. Imura, and Y. Osaka, Jpn. J. Appl. Phys., 25, L564 (1986).

7. H. Mimura, T. Futagi, T. Matsumoto, M. Katsuno Y. Ohta, and K. Kitamura, Appl. Surf. Sci., 65/66, 473 (1993)

8. A. S. Argon, V. Gupta, H. A. Landis, and J. A. Cornie, J. Mater. Sci., 24, 1207 (1989).

9. A. M. Haghiri-Gosnet, F. Rousseaux, B. Kebaki, F. R Ladan, C. Mayeux, A. Madouri, D. Decanini, J Bourneix, F. Carcenac, H. Launois, B. Wisniewski, E. Gat, and J. Durand, J. Vac. Sci. Technol. B, 8, 1565 (1990).

10. H. Windishman, J. Vac. Sci. Technol. A, 9, 2459 (1991)

11. W. Beyer, R. Hager, H. Schmidbaur, and G. Winterling, Appl. Phys. Lett., 54, 1666 (1989).

12. J. E. Spencer, R. Rausch, B. Su Mercer, B. Small, and S. Singh, 38th National Symposium of the American Vacuum Society, Seattle, WA (Nov. 1991)

13. F. J. Gómez, J. Martínez, J. Garrido, C. GómezAleixandre, and J. Piqueras, J. Non-Cryst. Solids, In press.

14. A. Guivarc'h, J. Richard, M. Le Contellec, E. Ligeon, and J. Fonteneille, J. Appl. Phys., 51, 2167 (1980).

15. M. J. Hernández, J. Garrido, and J. Piqueras, J. Vac. Sci. Technol. B, 12, 581 (1994).

16. D. E. Aspnes and J. B. Theeten, J. Appl. Phys., 50, 4928, (1979).

17. Handbook of Optical Constants of Solids, Vol. I, E. D. Palik, Editor, Academic Press Inc., Orlando, FL (1985).

18. R. M. Azzam and N. M. Bashara, in Ellipsometry and Polarized Light, Chap. 4, North-Holland, Amsterdam, (1984).

19. S. Ninomiya and S. Adachi, Jpn. J. Appl. Phys., 33, 2479, (1994).

20. M. H. Brodsky, M. Cardona, and C. Cuomo, Phys. Rev. $B, 16,3556$ (1977).

21. H. Wieder, M. Cardona and C. R. Guarnieri, Phys. Status Solidi $B, 92,99$ (1979).

22. J. Bullot and M. P. Schmidt, ibid., 143, 345 (1987).

23. A. C. Adams, Solid State Technol., 26, 135 (1983).

24. Y. Catherine and G. Turban, Thin Solid Films, 60, 193 (1979).

25. N. Saito, T. Yamada, Y. Yamaguchi, I. Nakaaki, and N. Tanaka, Philos. Mag., B52, 987 (1985)

26. S. Day, D. Das, and A. K. Barna, Solar Energy Mater. 15, 45 (1987). 
27. H. Rubel, B. Schroder, W. Fuhs, J. K. Krauskopf, T. Rupp, and K. Bethge, Phys. Status Solidi, 139, 131 (1987).

28. S. W .Rynders, A. Scheeline, and P. W. Bohn, J. Appl. Phys., 69, 2951 (1991).

29. D. K. Basa and F. W. Smith, Thin Solid Films, 192, 121 (1990).
30. Y. Katayama, K. Usami, and T. Shimada, Philos. Mag., B34, 283 (1991).

31. W. A. Lanford and M. J. Rand, J. Appl. Phys., 49, 2474 (1978).

32. K. Mui, D. K. Basa, and F. W. Smith, Phys. Rev. B, 25, 8089 (1987)

\title{
Effect of Temperature on the Interaction of Silicon with Nonionic Surfactants in Alkaline Solutions
}

\author{
Joong S. Jeon* and Srini Raghavan** \\ Department of Materials Science and Engineering, University of Arizona, Tucson, Arizona 85721, USA
}

Juan P. Carrejo

Motorola, Materials Characterization Laboratory, Mesa, Arizona 85062, USA

\begin{abstract}
The interaction of silicon wafers with alkaline solutions of octylphenol polyethylene oxide nonionic surfactants of different ethylene oxide chain length has been characterized at 25,50 , and $75^{\circ} \mathrm{C}$. Wettability of silicon wafers was improved significantly at higher temperatures. Surfactants with long ethylene oxide chains exhibited less adsorption than surfactants with short ethylene oxide chains, and increase in solution temperature resulted in increased adsorption. Generally, the addition of surfactants to alkaline solution decreased the surface roughness of silicon; however, the degree of reduction of surface roughness was influenced by the length of ethylene oxide chain and conditioning temperature.
\end{abstract}

\section{Introduction}

Ionic as well as nonionic surfactants are increasingly considered for use in buffered oxide etch (BOE) and alkaline cleaning solutions. The use of surfactants in BOE solution to render silicon hydrophilic has been in vogue for many years. ${ }^{1}$ The reduction of particulate contaminants on silicon surfaces is also feasible through the addition of surfactants to cleaning solutions. ${ }^{2}$ It is well known that the microroughness of silicon exposed to process solutions can be reduced through the use of suitable surfactants. ${ }^{3}$ For example, in alkaline solutions, silicon is etched according to the following reaction ${ }^{4}$

$$
\mathrm{Si}+2 \mathrm{H}_{2} \mathrm{O}+2 \mathrm{OH}^{-} \rightarrow 2 \mathrm{H}_{2}+\mathrm{Si}(\mathrm{OH})_{2}\left(\mathrm{O}^{-}\right)_{2}
$$

This etching reaction induces a rough silicon surface and consequently a rough $\mathrm{Si}-\mathrm{SiO}_{2}$ interface. Rough interfaces degrade electrical properties of thin oxide films such as breakdown electric field strength $\left(E_{\mathrm{BD}}\right)$ and charge to breakdown $\left(Q_{\mathrm{BD}}\right)$. $^{5}$ Surfactant addition to alkaline cleaning solutions such as choline and tetramethylammonium hydroxide (TMAH) is critical for controlling surface roughness.

Nonionic surfactants have been more popular than ionic surfactants because they do not leave any residual ions on silicon surfaces after deionized (DI) water rinsing steps. These surfactants typically belong to the category of polyethylene oxide alcohols or alkylphenol polyglycidol ethers. Despite the widespread use of these surfactants in silicon wafer cleaning and etching processes, fundamental investigations dealing with the interaction of these surfactants with hydrophobic Si surfaces are scarce. A recent publication by the authors presents a detailed analysis of the relative adsorption capacity of polyethylene oxide alcohol surfactants at ambient temperature. ${ }^{6}$ In this paper we clearly showed that surfactant adsorption is responsible for the reduction of microroughness of silicon exposed to alkaline solutions. Since elevated temperatures are used in

\footnotetext{
* Electrochemical Society Student Member.

** Electrochemical Society Active Member.
}

many cleaning processes, it is important to investigate the effect of temperature on the interaction of these surfactants with silicon. Here the results of an investigation undertaken to characterize the interaction of octylphenol polyethylene oxide (OPEO) surfactants with hydrophobic silicon through the measurements of wettability, adsorption/desorption, and microroughness at 25,50 , and $75^{\circ} \mathrm{C}$ are presented.

\section{Experimental \\ Materials}

In this research, OPEO nonionic surfactants of different ethylene oxide (EO) chain lengths were used. Specifically, surfactants represented by the chemical structure, $\mathrm{C}_{8} \mathrm{H}_{17^{-}}$ $\mathrm{C}_{6} \mathrm{H}_{4}-\left(\mathrm{OCH}_{2} \mathrm{CH}_{2}\right)_{n}-\mathrm{OH}(n=5,9.5,16$, and 30$)$ were used as received. Samples of these surfactants were kindly provided by Union Carbide. The selected properties of these surfactants are shown in Table I. Of particular importance is the cloud point which is the temperature at which nonionic surfactant solutions suddenly become turbid due to aggregation by dehydration of $E O$ chains.

For the measurements of wettability and surface roughness of silicon, $n(100) \mathrm{Si}$ wafers were cut into $13 \times 19 \mathrm{~mm}$ samples in a class 100 clean room. These samples were cleaned with a $4: 1$ mixture of $\mathrm{H}_{2} \mathrm{SO}_{4}$ and $\mathrm{H}_{2} \mathrm{O}_{2}$ (piranha) and then rinsed in DI water. The native oxide layer on the samples was removed using a 100:1 BOE solution. The samples were subsequently rinsed in DI water and dried using nitrogen gas. All surfactant solutions were prepared in electronic grade DI water and the $\mathrm{pH}$ of solutions was adjusted to $9.5 \pm 0.1$ with $\mathrm{NH}_{4} \mathrm{OH}$.

Table I. HLBa number and cloud point of OPEO surfactants.

\begin{tabular}{lllcc}
\hline Number of EO unit, $n$ & 5 & 9.5 & 16 & 30 \\
FLB number & 10.4 & 13.5 & 15.8 & 17.8 \\
Cloud point $\left({ }^{\circ} \mathrm{C}\right)$ (1\% solution) & $<0$ & 65 & $>100$ & $>100$ \\
\hline
\end{tabular}

${ }^{a}$ HLB: hydrophile-lipophile balance. ${ }^{6}$ 